\title{
APPLICATION OF WAVELET TRANSFORM IN DISCRIMINATION OF INTERNAL FAULT CURRENT AND MAGNETIZING INRUSH CURRENT OF POWER TRANSFORMER
}

\author{
ANIL K. AGAWANI ${ }^{1} \&$ ARCHANA G. THOSAR ${ }^{2}$ \\ ${ }^{1} P G$ Scholar, Department of Electrical Engineering, Government College of Engineering, Aurangabad, India \\ ${ }^{2}$ Faculty, Department of Electrical Engineering, Government College of Engineering, Aurangabad, India
}

ABSTRACT
Transmission of the power is the major challenge as utilities located at the remote places, hence proper
functioning of power transformer is to be maintained. Many times, transformer encounters with no-fault condition such
as inrush current, which results in unwanted tripping of transformer. So, it is necessary to discriminate fault and no-
fault condition on transformer, so that unwanted tripping of circuit breaker can be avoided and uninterrupted service
can be maintained.
This paper, present a technique based on the Continuous Wavelet Transform (CWT) to differentiate among
faulted and un-faulted condition on power transformer. Transformer modeling and simulation of faulty and healthy
condition are carried out using MATLAB/Simulink software. By employing CWT, suitable features are extracted as the
waveform resulted from the faulty condition, and healthy condition are different in nature, after first zero crossing of
fault current and Inrush current.
KEYWORDS: Inrush Current, Power Transformer \& Wavelet Transform

Received: Jun 13, 2017; Accepted: Jul 05, 2017; Published: Jul 31, 2017; Paper Id.: IJEEERAUG20176

\section{INTRODUCTION}

In recent years, many researchers in mathematics and signal processing have developed wavelet transform for analyzing signals in time and frequency domain. This transform is most suitable for non- stationary signals. Robert et al (1996) proposed the use of wavelet transform for analyzing electromagnetic transients associated with power system faults and switching. The frequency domain data produced by wavelet transform is useful for analyzing source of transients. The choice of mother wavelet for different power system applications have been proposed by santoso et al (1996). According to him, for short and fast transients, db2, db4, etc. are preferred and for slow transients, db8, db10 shows good results. Use of wavelet for Time resolution for high frequency components of fault transients is discussed by Fernando and Ali Abur (1998). The methods for calculating effective values of voltage and current in wavelet have been worked out by Zhu (2004).

Many techniques have been proposed to identify internal fault current and inrush current, these techniques were based on signal processing using fourier transform method, calculation of time interval between two peaks of fault current and two peaks of inrush current, calculation of peaks for both currents and comparing them to develop an appropriate algorithm or model. In this paper, 3-phase ground fault has been considered as faulted condition and Inrush current is taken as no fault condition on transformer [10]. 
Under abnormal condition, power transformers are protected by differential relay. This relays are often get tripped due to inrush current, which is developed during charging of the transformers. Hence, treatment of inrush current as fault current is the main drawback of the protection system. So, there is need to develop a system, which can differentiate between faulty i.e. internal faults and no fault i.e. inrush current. If the sensing of inrush current as fault current by relay will make the circuit breaker to operate, which is unreliable, since a large area is disconnected from being supplied. The malfunctioning of relay results in unreliable power system. Hence, the property of inrush current and fault current can be used to discriminate between them and stability of the power system is improved.

The mathematical tool called, wavelet is becoming popular method for condition monitoring of large transformers. Abnormal condition on power transformer has to be checked by disconnecting it, and then opening each part to locate the fault. This traditional method is time consuming and very expensive, also disconnecting it from utility is not good choice.

Hence, Wavelet Transform is used to analyze the signals, so that exact location of fault can be identified without opening or disconnecting power transformer and online condition monitoring can be done.

\section{FAULTS ON TRANSFORMER}

Although transformer is static device, due to abnormal system conditions, internal stresses arises. Generally, transformer is encountered with faults mentioned below

- Over current due to increased loads and external short circuits

- Fault at the terminal

- Faults in the winding

- Incipient faults

Thermal and mechanical stresses results from these faults in the winding of transformer and its terminals. Overheating is the result of thermal stresses, which ultimately affects the transformer by affecting its insulation system. Insulation deterioration leads to the development of faults in the winding. Sometimes, the cooling system of the transformer fails and results in overheating, hence safety of transformer is very important. The reactance of transformer helps in limiting the short circuit current of the electrical transformer and short circuit current is high at low reactance. The generally occurring winding faults are earth fault and inter turn fault. The incipient faults are nothing but the faults, which have no instant effect but, the persistence of this fault for long time may lead to the major fault. For example, the incipient faults can be due to damage of insulation between core and lamination, reduction in level of oil due to leakage, stoppage of oil flow paths. As a result, transformer overheats which may damage the insulation, hence resulting into short circuit $[1,6]$.

\section{INRUSH CURRENT}

It is an instantaneous current, drawn by transformer, when operating under no-load during starting. When transformer is initially energized, a large current 10 to 15 times the rated transformer current flows for several cycles. The inrush current is the result of hysteresis property of material as de-energizing a transformer retains some magnetism, which develops residual flux and when the transformer energizes, this residual flux voltage helps in developing a transient current of large magnitude known as Inrush Current. This current is not the fault current, as it flows only for few cycles and does 
not harm the transformer and flows only in the one part of differential relay. The residual flux depends on

- $\quad$ capacitance of winding

- characteristics of transformer core material

- current chopping characteristics of circuit breaker

- $\quad$ core gap factor etc.

The magnitude and the time length of inrush current depends on transformer size, power system size, switching instant, material of core of transformer [13].

The equation for generation of inrush current is given in (1), where a three phase transformer is connected to AC supply. $v$ and $\lambda$ are the instantaneous flux in the core and voltage drop across the primary winding.

$$
v \equiv \frac{d \lambda}{d t}
$$

We can say from equation (1) that flux wave form is the integral of voltage wave form and in operating transformer these are shifted $90^{\circ}$. For energizing transformer, the flux initially starts from zero point, so voltage starts from zero point, flux will reach approximately twice its peak as it integrates the area under the voltage curve, for first half cycle, leading to the saturation of transformer. During saturation, disproportionate amount of flux has to be provided, which is meet by mmf produced by winding current in the core, and hence flux becomes double of its normal peak. Thus, generates nearly ten times large current know as magnetizing inrush current.

The general equation of magnetizing inrush current can be expressed as

$$
i(t) \equiv \frac{\sqrt{2} \nu_{m}}{\mathrm{Z}_{t}} * \mathrm{~K}_{w} * \mathrm{~K}_{s} *\left(\sin (\omega t-\phi)-e^{\frac{-\left(t-t_{0}\right)}{t}} \cdot \sin \alpha\right)
$$

Where,

$\boldsymbol{V}_{m}:$ Maximum applied voltage;

$Z_{t}:$ Total impedance under inrush, including system;

$\phi:$ Energization angle;

$\boldsymbol{t}$ : Time; $t_{0}$ : Point at which core saturates;

$\tau$ : Time constant of transformer winding under inrush conditions;

$\alpha$ : function of $t_{0}$

$\boldsymbol{K}_{w}$ : Accounts for 3 phase winding connection;

$\boldsymbol{K}_{t}$ : Accounts for short-circuit power of network. 
Figure 1. shows inrush current resulted from simulation in MATLAB for the proposed system for $1 \mathrm{~ms}$ duration.

\section{SYSTEM DISCRIPTION}

The system under study is composed of a 3 phase synchronous generator delivering power to load through 3 phase power transformer. A 3 phase transformer protected differential relay is by employing two circuit breakers on primary as well as secondary.

The difference between the currents of two CBs, which are the outputs of primary as well as secondary is given to the proposed relay. The developed system is composed of

- Three phase 3000MVA power source, $120 \mathrm{kV}$

- Two- three phase circuit breakers on the transformer sides.

- Three phase star/star 47MVA, 120/25 KV power transformer.

- 3-30 KM feeder.

- Three phase load.

- The required current transformers

As it is known that fault current is cause of residual magnetism in the core, hence core parameters were adjusted to obtain inrush current, and fault current can be obtained by three phase ground fault in matlab/Simulink model.

Table 1 shows transformer parameters used for the simulation.

Table 1: Simulated Transformer Main Parameters

\begin{tabular}{|l|c|}
\hline \multicolumn{1}{|c|}{ Parameters } & Ratings \\
\hline Transformer Connection & Y/Y \\
\hline Rated power & $47 \mathrm{MVA}$ \\
\hline Voltage Ratio & $120 / 25 \mathrm{kV}$ \\
\hline Rated Frequency & $50 \mathrm{~Hz}$ \\
\hline Primary winding Resistance/phase & $0.003 \mathrm{pu}$ \\
\hline Primary winding Inductance/phase & $0.09 \mathrm{pu}$ \\
\hline Secondary winding Resistance/phase & $0.003 \mathrm{pu}$ \\
\hline Secondary winding Inductance/phase & $0.09 \mathrm{pu}$ \\
\hline Core resistance & $300 \mathrm{pu}$ \\
\hline Magnetizing Reactance & $300 \mathrm{pu}$ \\
\hline
\end{tabular}

In this model, Wavelet based discrimination technique is used to distinguish between fault and no fault situation in transformer.

\section{SIMULATION OF FAULT CURRENT AND INRUSH CURRENT}

The developed model is used to carry out simulation of fault current as well as inrush current. Since inrush current is result of residual magnetism, hence in modeling of transformer, its core saturation behavior is considered. Simulations results for the two currents are shown in Figure 2.and Figure 3. From the result, we can see that both waveforms are different in nature, in case of inrush current, the magnitude is increasing abruptly for few seconds and decreasing at fast rate, and in case of fault current, magnitude increases for few cycles, but after its magnitude remains constant if not interrupted by circuit breaker. Developed star/star transformer matlab/Simulink of the power system model is shown in 
Figure 1.

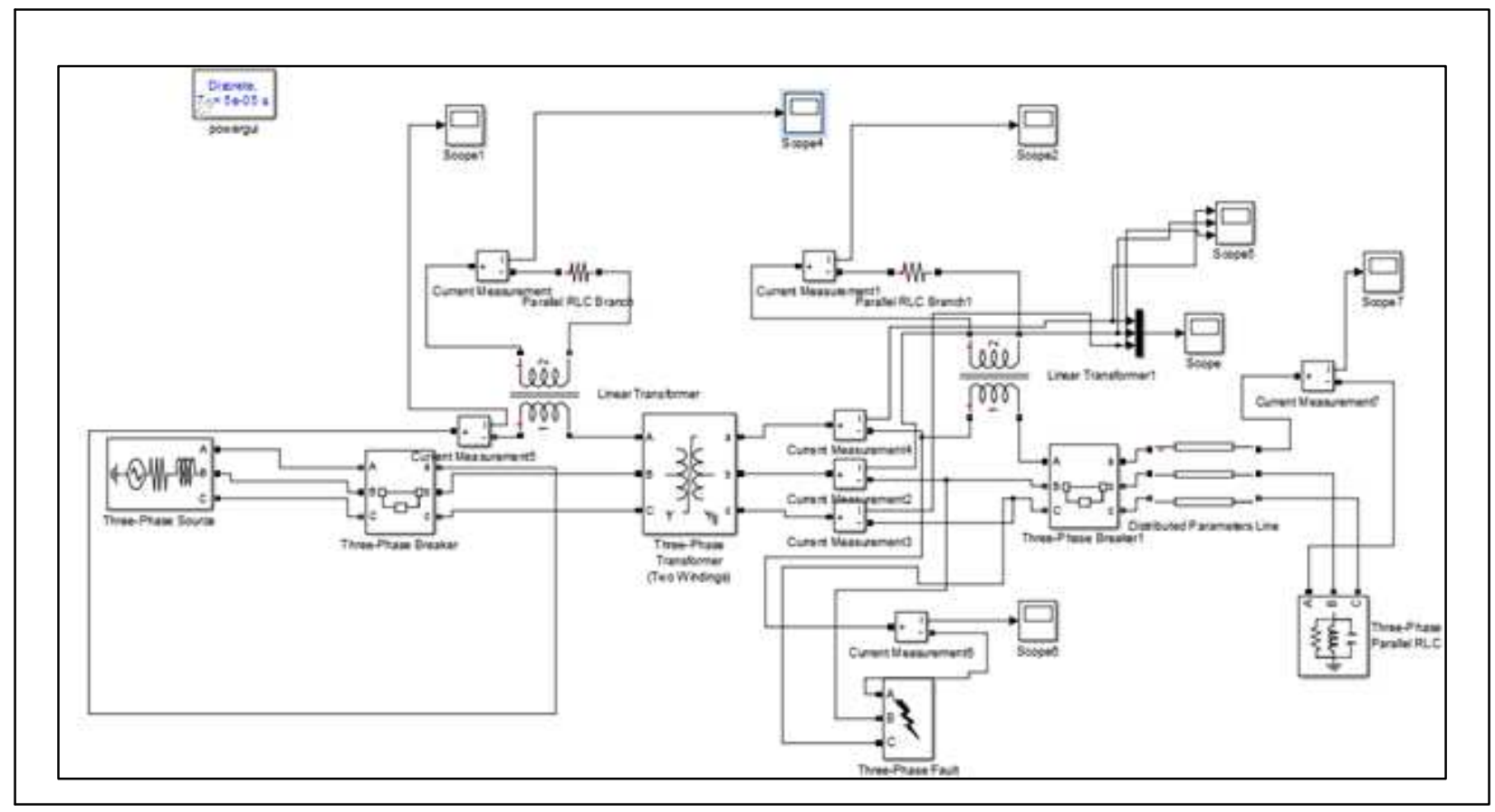

Figure 1: Developed Star/Star Transformer Matlab/Simulink of Power System Model

The discrimination between fault current and inrush current can be done by using the characteristics of both curves, as inrush current curve has small slope at starting and as it progress its slope, gradually increases. Moreover, DC components in inrush current are more and last for few cycles, but in case of fault current, the slope of the curve is more at every situation and DC components are very rare. Though the difference in both cases is very small, but they are sufficient to distinguish between fault and no fault condition of transformer.

The early method of discrimination i.e. differential protection was based on harmonic content of differential current. In which, the ratio of second harmonic to the fundamental component of differential current for fault current would be less than inrush current. Hence, clearing of faulty condition has been successful, but the main drawback of this method was the harmonic production, which is also possible due to saturation of CTs and long transmission lines, so, there was possibility of operating differential relay under no fault condition, also hence this method is unreliable.

The other methods used were based on fluctuating waveforms of differential relay and time difference between two peaks of internal fault current and inrush current. From studies, it has been proved that difference in time for fault current is less than inrush current. Wavelet based discrimination technique has shown great advantage in identifying as well as clearing fault when occurred, as it is very effective and fast technique which can clearly recognize difference between fault and no-fault condition on the transformer. In this technique, different samples can be obtained for few cycles of fault as well as inrush current. Then, this data can be compared in terms of their magnitude and then can be used to actuate the differential relay. 


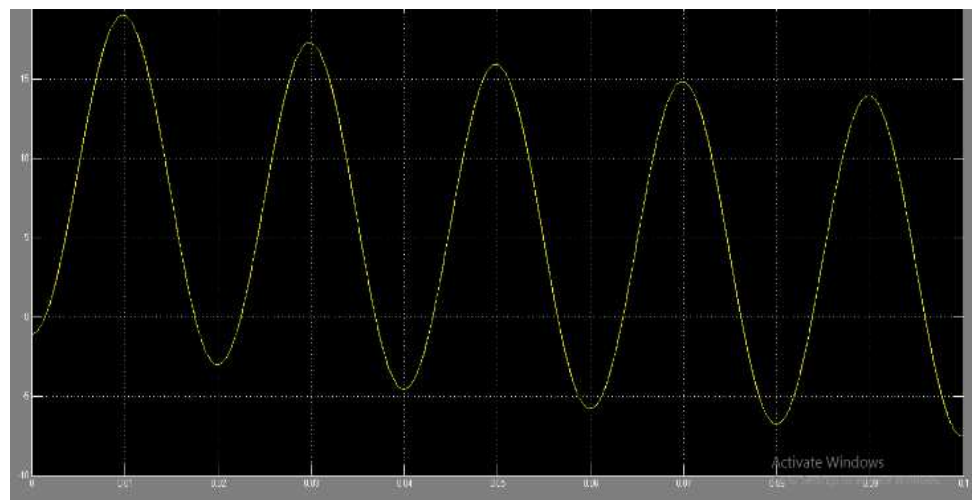

Figure 2: First Four Cycles of Internal Fault Current

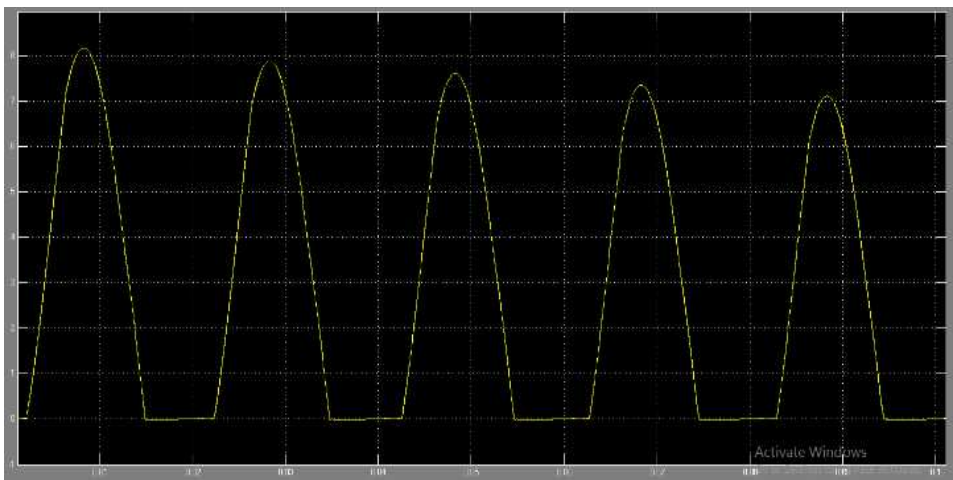

Figure 3: First Four Cycles of Inrush Current

\section{WAVELET TRANSFORM}

A mathematical tool for analyzing the signal is Wavelet Transform. It is the extension of Fourier Transform method. This method provides the information regarding the frequency component present in the signal at particular time.

There are two types of wavelet transform, Continuous Wavelet Transform (CWT) and Discrete Wavelet Transform (DWT). CWT uses inner products to measure the similarity between a signal and an analyzing function. It is defined as, the sum over all time of the signal multiplied by scaled, shifted versions of the wavelet function. Calculating wavelet coefficients at every possible scale is a fair amount of work, and it generates an awful lot of data. In DWT, we choose only a subset of scales and positions at which to make our calculations.

A mathematical tool for analyzing the signal is Wavelet Transform. It is the extension of Fourier Transform Method. This method provides the information regarding the frequency component present in the signal at particular time.

There are two types of wavelet transform, Continuous Wavelet Transform (CWT) and Discrete Wavelet Transform (DWT). CWT uses inner products to measure the similarity between a signal and an analyzing function. It is defined as the sum over all time of the signal, multiplied by scaled, shifted versions of the wavelet function. Calculating wavelet coefficients at every possible scale is a fair amount of work, and it generates an awful lot of data. In DWT, we choose only a subset of scales and positions at which to make our calculations.

\section{CONTINUOUS WAVELET TRANSFORM}

Wavelet means a small wave function and compactly supported. The standard function for generating the other window functions is mother wavelet. At lower frequencies WT has excellent frequency and poorer time resolution, and at 
higher frequencies the WT has excellent time and poorer frequency resolution.

The continuous signal $\mathrm{x}(\mathrm{t})$ can be expressed in Wavelet Transform as

$$
W T(\alpha, \tau)=\frac{1}{\sqrt{\alpha}} \int_{-\infty}^{\infty} x(t) * g\left(\frac{t-\tau}{\alpha}\right) d t
$$

Where, $g\left(\frac{t-\tau}{\alpha}\right)$ is an analogous function used to transform signal $\mathrm{x}(\mathrm{t})$. The characteristics of analyzing function $g(t)$ is that it must be short and oscillatory.

$\alpha=$ Dilation Factor or scale, in terms of frequency, global details of a signal can be acquired from low frequencies and information regarding hidden pattern can be obtained from high frequencies. Mother wavelet $g\left(\frac{t-\tau}{\alpha}\right)$

can be expanded or contracted in time depending on whether $\alpha>1$ or $\alpha<1$. If $\alpha>1$ then signal is expanded in time and if $\alpha<1$ then it is contracted in time.

$\tau=$ translational factor, gives information of time.

Various mother wavelets have been derived such as Daubechies wavelet, Haar wavelet, Symlet, Biorthogonal, Coiflet for analysis of signal into a set of approximate and detailed coefficients. It uses MRA (Multi Resolution Analysis) method to extract the information of the signal $[4,10]$.

\section{DAUBECHIES WAVELET}

The explicit function of dblis Haar Wavelet other than these Daubechies $(\mathrm{db})$ wavelet has no exact expression. The $\mathrm{db}$ can also be written as dbN where $\mathrm{N}$ is the order. db having Supporting length of $\psi$ and $\phi$ is $2 \mathrm{~N}-1$. The number of vanishing moments are more, hence analysis of signal is made more clear.

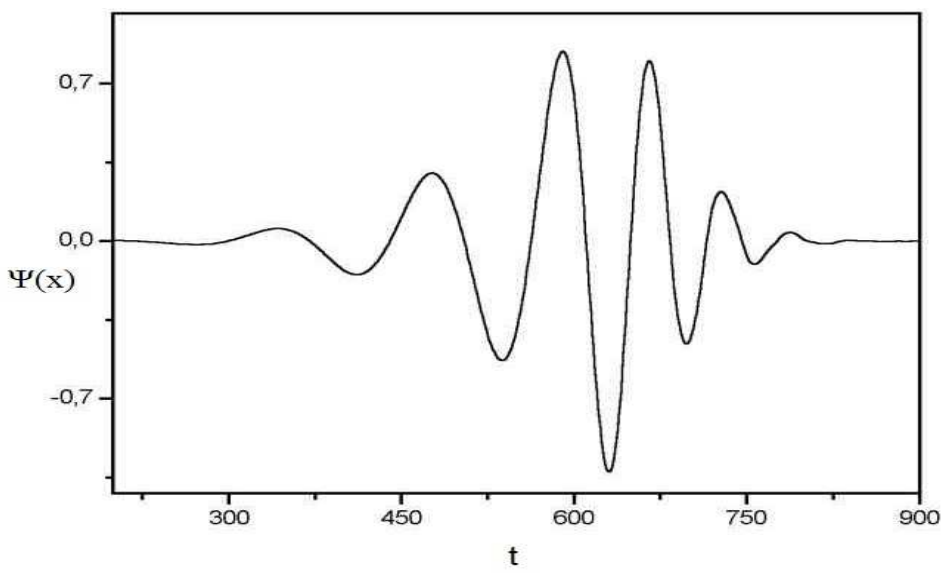

Figure 4: Daubechies Wavelet

$\mathrm{N}$ is also the number of vanishing moments in $\psi$. db wavelets are not symmetrical and most of the functions are regular at certain points. 


\section{SIMULATION RESULTS AFTER APPLYING CWT}

The proposed system in Figure 1 is simulated in MATLAB/Simulink and results are shown in Figure 5 and Figure 6.for daubechies wavelet (db4), applied at level 5 for the fault current and inrush current. The reason of choosing db4 is that the fault and inrush current are short and fast signals, and according to santoso et al (1996), for such signals, db2 and $\mathrm{db} 4$ are preferred so as to extract more information.

Different levels of wavelets applied on the internal fault current obtained from simulation are shown in Figure 5. The frequencies generated due to fault can be seen. The 5 levels show different characteristics and coefficients are also different. The time span taken for internal fault is $t=77 \mathrm{~ms}$ and resultant frequency (db5-db1) is shown in Figure 5 and Figure 6. For comparison purpose, we chose db1 coefficients and from the Figure 7, the characteristics are compared. In the same way, the fault current is restricted to only for four cycles, and the analysis is made and frequency levels from wavelet are demonstrated.

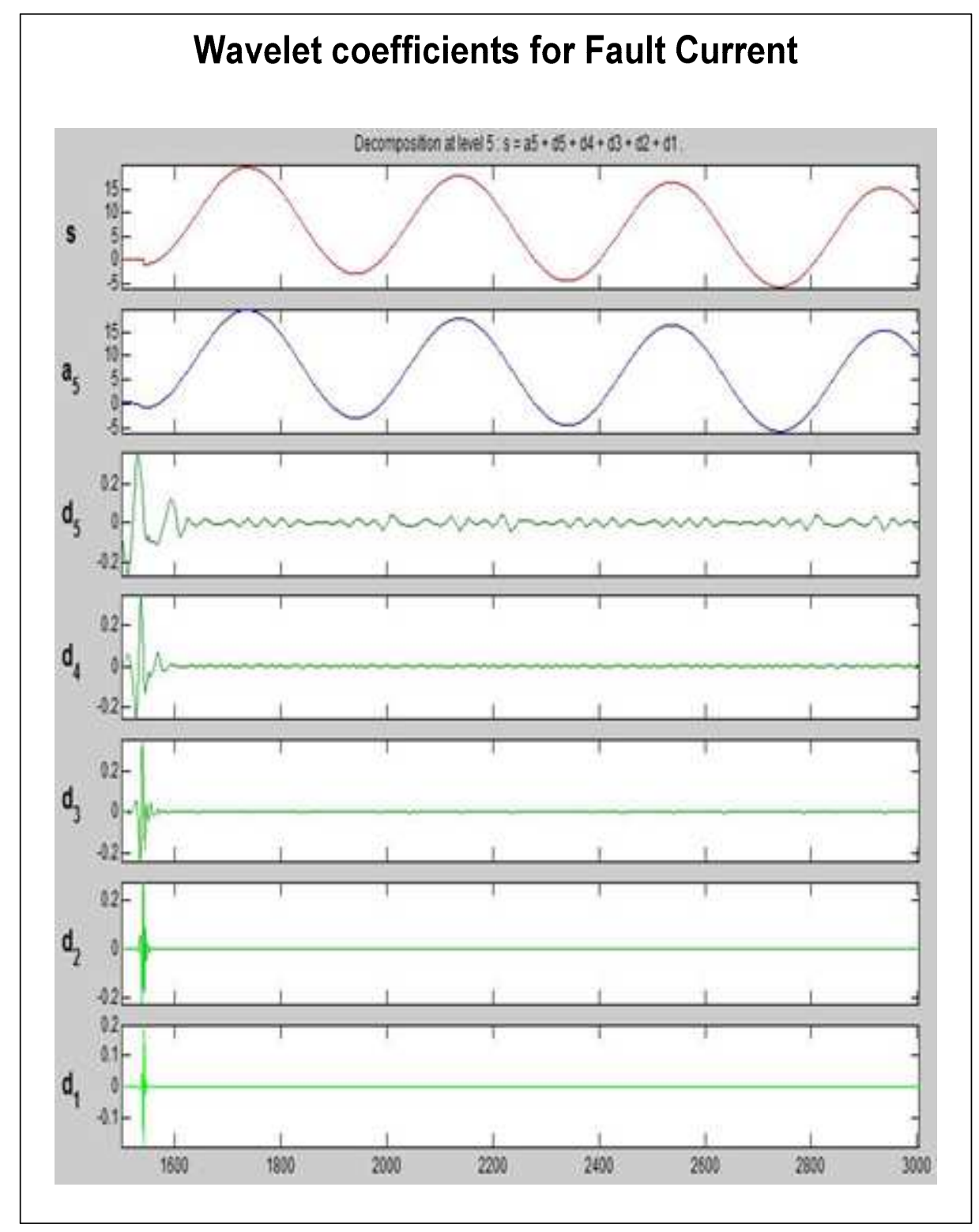

Figure 5: Wavelet Coefficients for Internal Fault Current 
Wavelet coefficients shown in Figure 6.are also obtained by applying different levels of daubechies wavelet for analyzing the inrush current resulted from simulation of the proposed model as shown in Figure 1.

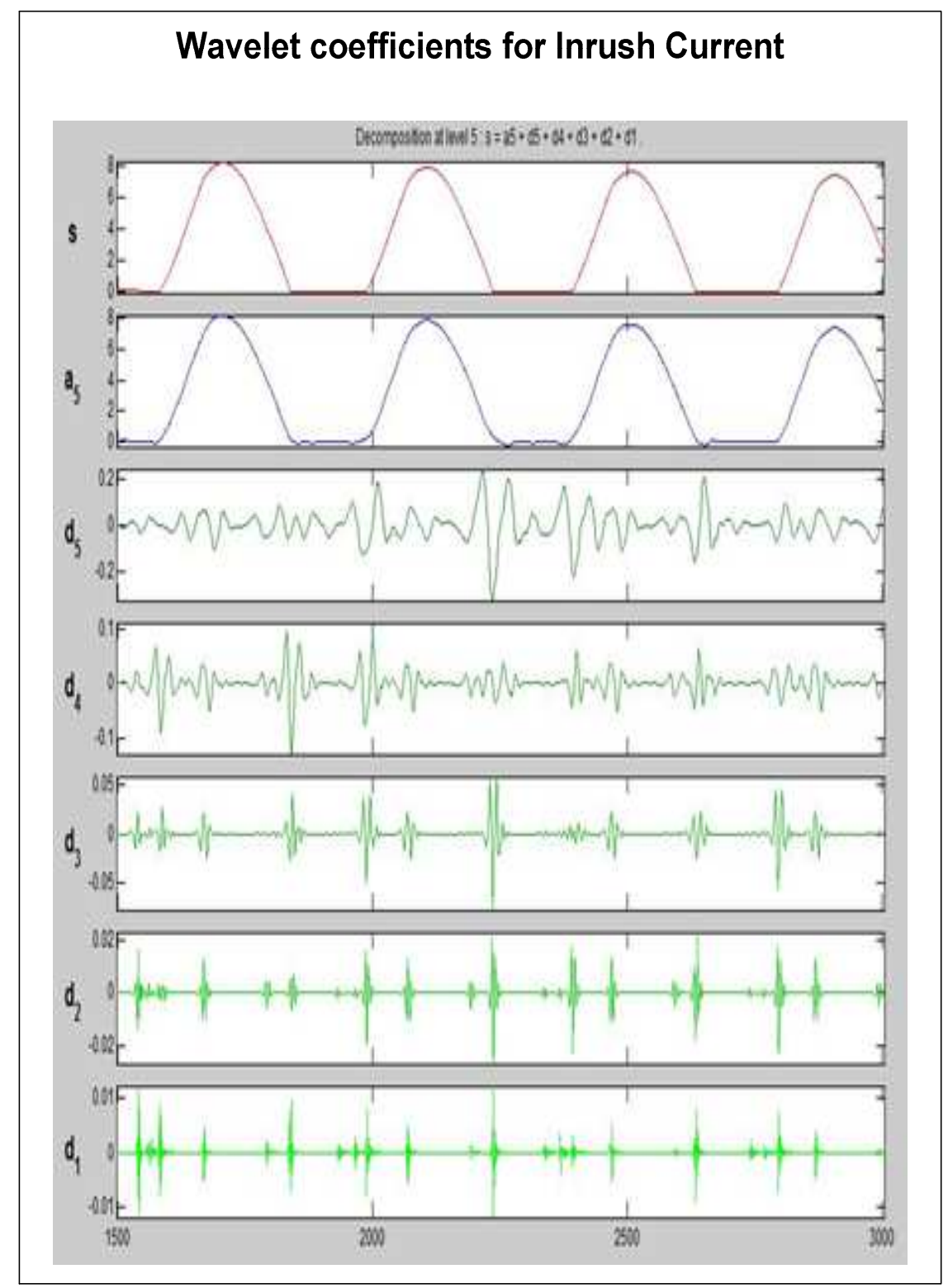

Figure 6: Wavelet Coefficients for Inrush Current

The wavelet coefficients shown in Figure 5.and Figure 6.are arranged as db5, db4, db3, db2, db1 in descending order.

Figure 7 presents the profile of db4 applied for level 1 for internal fault current and magnetizing inrush current respectively, and is used for discrimination purpose. Few values of coefficients can be taken for comparison of both the conditions. 60 coefficients are taken for discrimination purpose and the range can be seen in Figure 7. d1 components are considered for discrimination purpose, so that a clear difference in magnitude and frequency is obtained. The difference in both the signals is observed only for first four cycles, since the magnitude of inrush current is more for first few cycles. Different profiles can be obtained by considering $\mathrm{d} 5, \mathrm{~d} 4, \mathrm{~d} 3, \mathrm{~d} 2$, and $\mathrm{d} 1$. This technique can be validated considering the signatures of both internal fault current and inrush current after first zero crossing. 


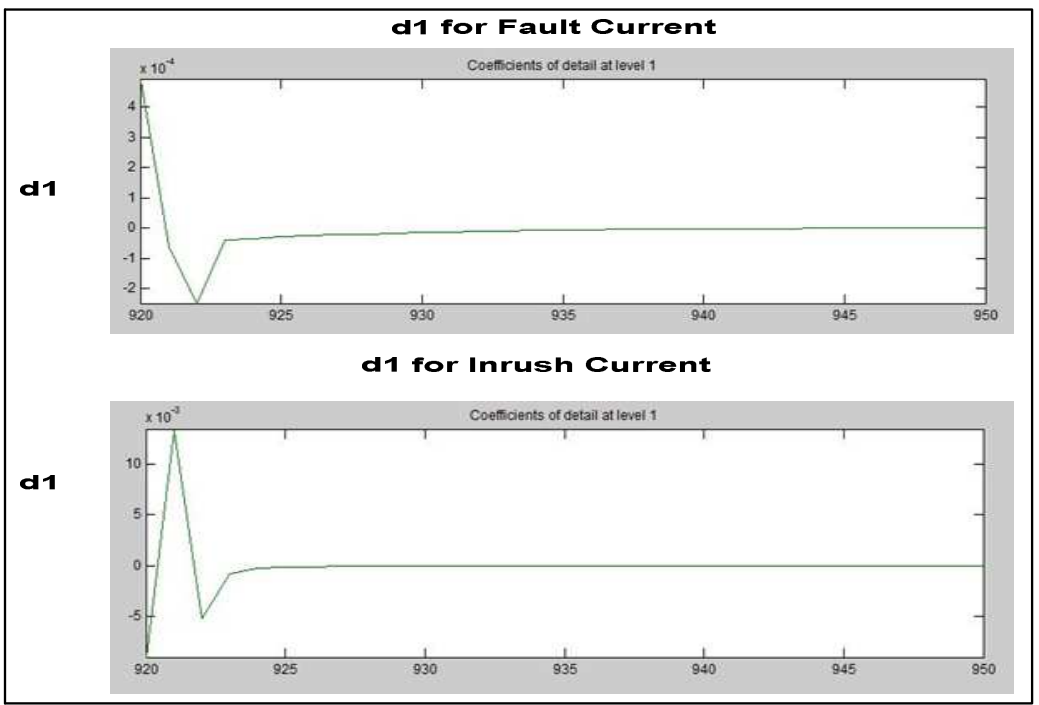

Figure 7: D1 WT Coefficients for Fault Current and Inrush Current

The analysis is made for values of $\mathrm{db} 1$ wavelet coefficients and these coefficients for internal fault current are more than the corresponding values for inrush current and this is given for one half cycle in Figure 8.and Figure 9.

Also, the slope of inrush current is very less initially, and gradually increasing reaching the next cycle, but the slope of fault current is sharper.

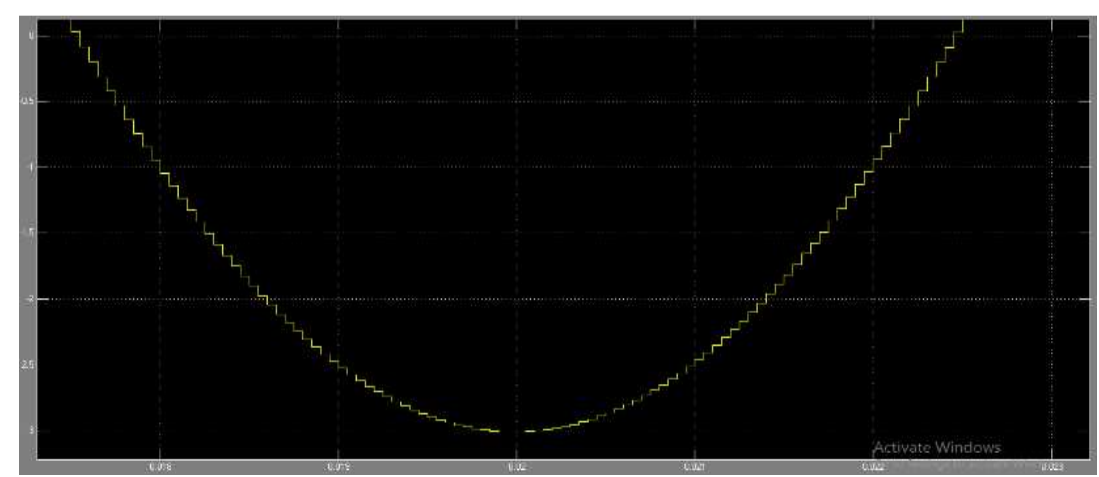

Figure 8: Internal Fault Current after First Zero Crossing

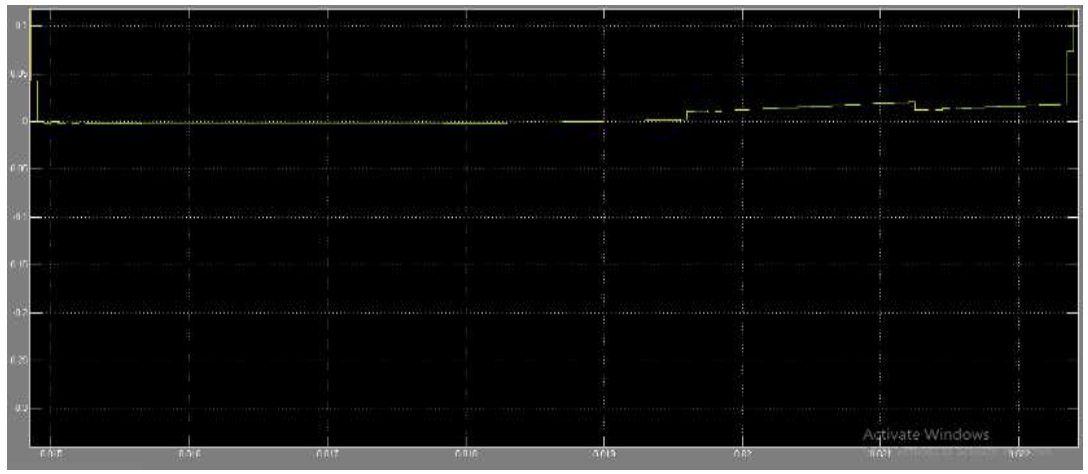

Figure 9: Inrush Current after First Zero Crossing

So, after first zero crossing as shown in Figure 8.and Figure 9, it can be observed that values obtained from both wavelet coefficients varies drastically. After zero crossing, the values of wavelet coefficients in case of inrush current are 
first negative, then after quarter cycle they are positive, but for internal fault current they are always negative. These values are used to discriminate between internal fault current and inrush current in the power transformer. These values are sufficient to make the relay sense, the fault correctly by making decision that, inrush currents are not the faults. The values obtained from this technique can be used as input to the digital relay for decision making purpose, so that unwanted tripping is avoided and uninterrupted supply can be provided during no-fault condition. This will not only make the power system efficient, but life of protection system also get enhanced. For implementation purpose, the initial cost of the power system increases, but running cost will drastically come down because of proper functioning of differential relay.

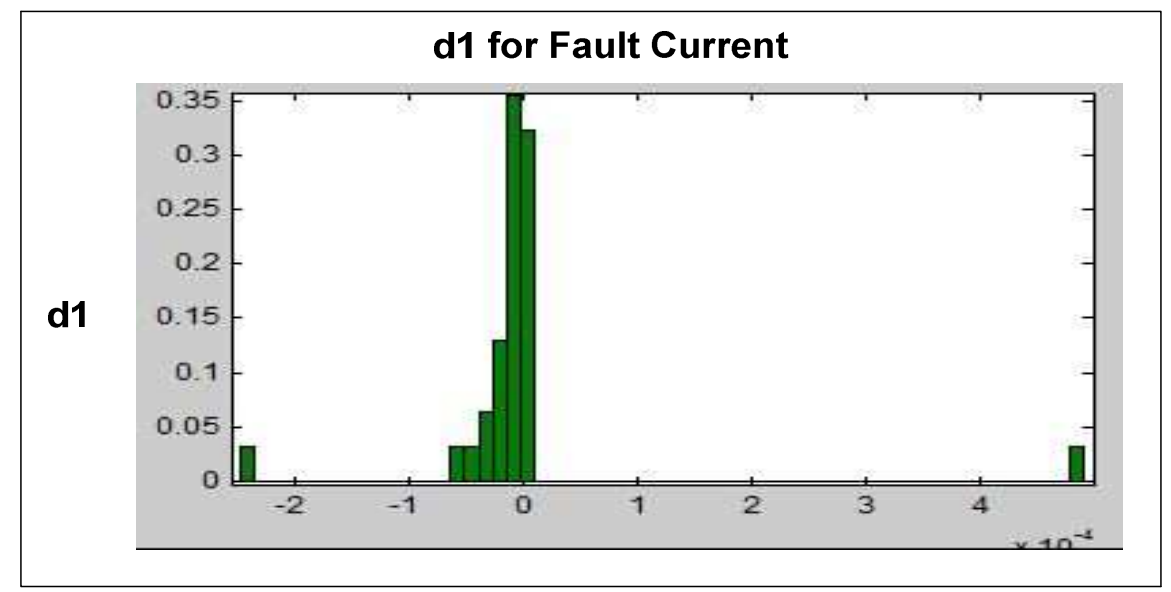

Figure 10: Elements of d1 Wavelet Coefficients for Fault Current

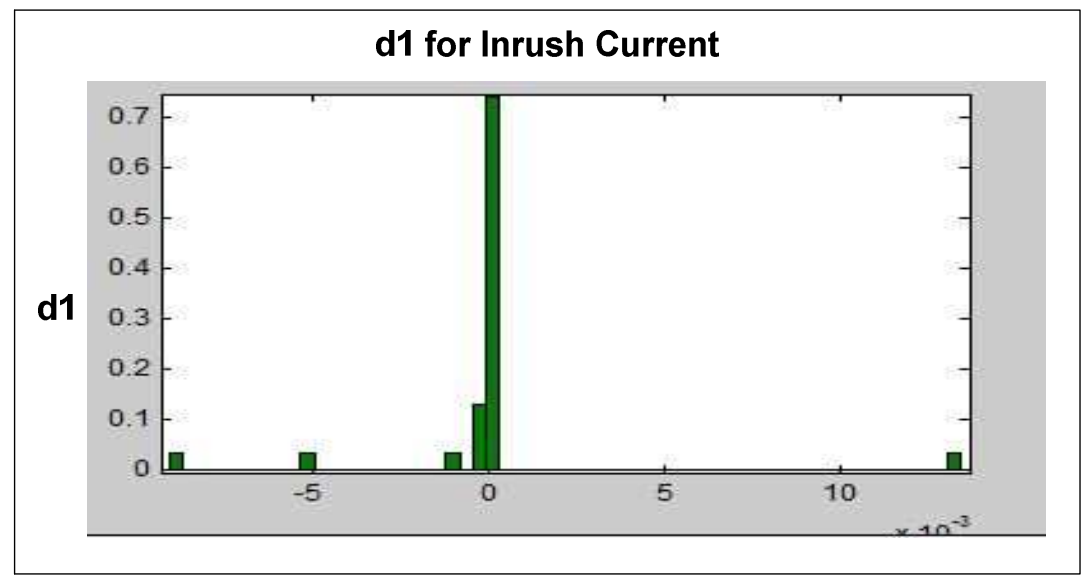

Figure 11: Elements of d1 Wavelet Coefficients for Inrush Current

Figure 10 and Figure 11 shows the elements of d1 wavelet coefficients obtained for both cases and are sufficiently different to discriminate internal fault current and magnetizing inrush current, and these values can be given to digital relays.

\section{CONCLUSIONS}

We studied different types of faults occurring on transformer and characteristics of inrush current. The brief study of wavelet transform is made along with daubechies wavelet, so that analysis of the signal can be understood clearly. Also, the simulation of internal fault current and magnetizing inrush current for developed model of power transformer has been done and coefficients are extracted. Differences between the magnitudes of wavelet transform coefficients in specific band of frequency, obtained from internal fault and inrush currents. This element of d1 wavelet coefficients are used for 
discrimination purpose, as they are sufficiently different in both cases of fault and no-fault condition. The wavelet transform method has been proved to be the efficient method and fast technique to discriminate transformer internal fault and no fault condition. This can be again simulated in Fuzzy Logic.

\section{REFERENCES}

1. S. Birlasekaran and F. Fetherston, "Off/On-Line FRA condition monitoring technique for power transformer," IEEE Power Eng. Rev., vol.19, no. 8, pp. 55-56, Aug. 1999.

2. S. Birlasekaran, Fred Fetherson. "On-Line FRA Condition Monitoring Techniques for Power Transformers". IEEE Power Engineering Review, pp 54-56 Agost- 1999.

3. E. Gómez-Luna, G. Aponte, C. Gonzalez-Garcia, and J. Pleite, "Current status and future trends in the frequency response analysis (FRA) with the transformer in service,” IEEE Trans. Power Del., vol. 28, no. 2, pp. 1024-1031, Apr. 2013.

4. D. C Robertson, O. I. Camps, J. S.Mayer, andW. B. Gish, “Wavelets and electromagnetic power system transients," IEEE Trans. PowerDel., vol. 11, no. 2, pp. 1050-1058, Apr. 1996.

5. E. Gómez-Luna, D. Silva, G. Aponte, J. Pleite, and D. Hinestroza, "Obtaining the electrical impedance using wavelet transform from the time response," IEEE Trans. Power Del., vol. 28, no. 2, pp. 1242-1244,Apr. 2013.

6. K. Butler-Purry and M. Bagriyanik, “Characterization of transients in transformers using discrete wavelet transforms," IEEE Trans. PowerSyst., vol. 18, no. 2, pp. 648-656, May 2003.

7. M. Wang, A. J. Vandermaar, and K. D. Srivastava, "Review of condition assessment of power transformers in service," IEEE Elect. Insul.Mag., vol. 18, no. 6, pp. 12-25, Nov. 2002.

8. Barry H. Ward, Stan Lindgren "A Survey of Developments in Insulation Monitoring of Power Transformers" Conference Record of the 2000 IEEE Intemational Symposium on Electrical Insulation, Anaheim, CA USA, April 2-5,2000.

9. Jouni K. Pylvänäinen, Kirsi Nousiainen, and Pekka Verho"Studies to Utilize Loading Guides and ANN for Oil-Immersed Distribution Transformer Condition Monitoring” IEEE transactions on power delivery, vol. 22, no. 1, january 2007.

10. N.C. Joshi, Y.R. Sood, R.K. Jarial and Rakesh Thapliyal "Transformer Internal Winding Faults Diagnosis Methods: A Review” MIT International Journal of Electrical and Instrumentation Engineering, Vol. 2, No. 2, Aug. 2012, pp. (77-81) 77.

11. Bhandari, A. K., M. Gadde, A. Kumar, and G. K. Singh. "Comparative analysis of different wavelet filters for low contrast and brightness enhancement of multispectral remote sensing images", 2012 International Conference on Machine Vision and Image Processing (MVIP), 2012.

12. E. Gomez-Luna, G. Aponte Mayor and J. Pleite Guerra, "Application of Wavelet Transform to Obtain the Frequency Response of a Transformer From Transient Signals-Part II: Practical Assessment and Validation," in IEEE Transactions on Power Delivery, vol. 29, no. 5, pp. 2231-2238, Oct. 2014.

13. Steve Mackay, "Practical Power Systems Protection",IDC Technologies, Perth, Australia, 2004.

14. P.L. Mao, R.K. Aggarwal, "A wavelet transform based decision making logic method for discrimination between internal faults and inrush currents in power transformers", Elect. Power Energy Syst., Vol. 22, pages 389-395, 2000.

15. K. Inagaki and M. Higaki, "Digital protection method for power transformers based on an equivalent circuit composed of inverse inductance," IEEE Trans. Power Del., vol. 4, no. 4,page(s): 1501-1510, Oct. 1998.

16. Omar A.S. Youssef, "Combined Fuzzy-Logic Wavelet-Based Fault Classification Technique for Power System Relaying", IEEE Transactions on Power Delivery, Vol. 19, Issue 2, Page(s): 582-589, April 2004. 